\title{
Insight into the WNT system and its drug related response
}

\author{
S. Tamanini, L. Idolazzi, D. Gatti, O. Viapiana, A. Fassio, M. Rossini \\ Rheumatology Unit, University of Verona, Italy
}

\begin{abstract}
SUMMARY
The WNT signalling pathway is a complex system for transferring information for DNA expression from the cell surface receptors to cytoplasm and then to the nucleus. It is based on several proteins that work together as agonists and antagonists in order to maintain homeostasys and to promote anabolic processes.

The WNT system acts on all cellular lines involved in bone resorption and formation. WNT pathway can mainly be triggered by two different signalling cascades. The first is well known and is the so-called WNT-beta catenin system (or the canonical pathway), the second is known as the non canonical WNT pathway.

WNT proteins form a superfamily of secreted glycoproteins. The association with surface receptors, called Frizzled, that are members of the $\mathrm{G}$ protein-coupled receptors superfamily and co receptors like low-density lipoprotein receptor-related proteins 5 and 6 (LRP5/6) complete the WNT system. LRP5/6 show high affinity for WNT antagonists that modulate the activity of this pathway: DKK1 and sclerostin (SCL), that play a crucial role in modulating the WNT system. The WNT-pathway and in particular its antagonists SCL and DKK1 seems to play a key role in the regulation of bone remodeling during treatment with bone active agents such as bisphosphonates, but not only. Their effects become relevant especially in the course of long-term treatments. Key words: WNT, DKK1, Sclerostin, Bisphosphonate.
\end{abstract}

Reumatismo, 2013; 65 (5): 219-230

\section{INTRODUCTION}

T his year is the thirtieth anniversary of the published report that announced the discovery of what proved to be the first mammalian WNT gene involved in mouse breast cancers with the evidence of its rule as proto-oncogene transcriptionally activated by viruses in multiple independent tumors (1).

Since then it was clear that $W N T$ genes and components of WNT signalling pathways are implicated in a wide spectrum of important biological phenomena, ranging from early organ development to cell behaviour in several diseases, not only cancers.

The WNT signalling pathway is a complex system for transferring information for DNA expression from the cell surface receptors to cytoplasm and then to the nucleus.

WNTs are a large family of 19 secreted glycoproteins that trigger multiple signalling cascades that are essential for embryonic development and tissue regeneration (2). WNTs represent the driving system of the embryo and determine body axes and drive organs growing in the right direction (3). In addition, WNT signalling orchestrate morphogenesis during embryonic development and this signalling pathway is critical for the maintenance of adult stem cell compartments in the bone, hematopoietic and gastrointestinal system. Another important task of WNT system is the maintenance of self-renewing tissues such as bone marrow, gut and skin.

The WNT pathway is a rather complex signalling system. On the plasma membrane of mammalian cells, any combination of 19 soluble WNT ligands and 10 WNT receptors of the Frizzled (FZ) protein family and several co-receptors and at least four classes of secreted WNT signalling modulators [secreted FZ-related protein family (SFRP), Dickkopfs (Dkks), Rspondins and WIF] can be present (4).

Aberrant WNT signalling results in developing malformation and underlies different human pathologies such as colorectal cancer, osteoporosis and neurodegenerative disorders (3). Proteins involved in the am-
Corresponding author: Silvia Tamanini Rheumatology Unit University of Verona Piazzale A. Stefani, 1 - 37126 Verona, Italy E-mail: silvia.tamanini@yahoo.it 
plification and transduction of WNT signals are often altered in cancer or lineage progenitor cells, leading to abnormal cell cycle control and/or altered cell fate decisions.

Any mutations in several WNT pathway components might also contribute to human skeletal dysplasia (2) (Tab. I).

\section{WNT AND BONE}

The molecular links between WNT signalling and bone development and remodelling were discovered by observing mutations in the WNT coreceptor low-density lipo- protein receptor-related protein 5 (LRP5). These mutations are linked to alterations in human bone mass (5-8). The discovery that activating and inactivating mutations in a WNT co-receptor can lead both to high bone mass and low bone mass in human beings, demonstrated that WNT signalling is a dominant regulator of bone density in humans and this point was then confirmed also in mouse genetic studies (9). Even small changes in the intensity, amplitude and duration of WNT signalling are able to interfere with skeletal development as well as bone remodelling, regeneration and repair during life. In addition, a number of polymorphisms in different WNT pathway

Table I - Human diseases associated with mutations of the WNT signaling components.

\begin{tabular}{|c|c|c|c|}
\hline Gene & Altered function & Type of alteration & Disease \\
\hline PORCN & $\begin{array}{l}\text { Enhancing WNT lipid modification/ } \\
\text { processing }\end{array}$ & LOF & X linked focal dermal hypoplasia \\
\hline Wnt3 & Enhancing ligands for WNT signaling & LOF & Tetramelia \\
\hline Wnt4 & Enhancing ligands for WNT signaling & LOF & Mullerian-duct regression and viriliation \\
\hline Wnt5b & Enhancing ligands for WNT signaling & Unknown & Type II diabetes \\
\hline Wnt7a & Enhancing ligands for WNT signaling & LOF & Fuhrmann syndrome \\
\hline Wnt10a & Enhancing ligands for WNT signaling & LOF & Odonto-onycho-dermal hypoplasia \\
\hline Wnt10b & Enhancing ligands for WNT signaling & LOF & Obesity \\
\hline RSPO1 & Enhancing WNT agonists & LOF & XX sex reversal - Hyperkeratosis \\
\hline RSPO4 & Enhancing WNT agonists & LOF & $\begin{array}{l}\text { Autosomal recessive anonychia- } \\
\text { hyponychia congenita }\end{array}$ \\
\hline SOST & Inhibition of LRP $5 / 6$ antagonists & LOF & Sclerostosis/Van Buchem disease \\
\hline Norrin (NDP) & $\begin{array}{l}\text { Enhancing specific ligands during } \\
\text { eye development }\end{array}$ & LOF & - \\
\hline LRP5 & Enhancing WNT coreceptors & $\begin{array}{l}\text { GOF } \\
\text { LOF }\end{array}$ & $\begin{array}{l}\text { Hyperparathyroid tumors } \\
\text { High bone mass } \\
\text { Osteoporosis-pseudoglioma } \\
\text { FEVR eye vascular defects } \\
\text { Early coronary disease and } \\
\text { osteoporosis }\end{array}$ \\
\hline LRP6 & Enhancing WNT coreceptors & LOF & $\begin{array}{l}\text { Early coronary disease and } \\
\text { osteoporosis }\end{array}$ \\
\hline FZD4 & Enhancing WNT receptors & LOF & Familial exudative vitreoretinopathy \\
\hline Axin 1 & $\begin{array}{l}\text { Inhibition of beta-catenin } \\
\text { degradation }\end{array}$ & LOF & Caudal duplication, cancer \\
\hline Axin 2 & $\begin{array}{l}\text { Inhibition of beta-catenin } \\
\text { degradation }\end{array}$ & LOF & Tooth agenesis, cancer \\
\hline APC & $\begin{array}{l}\text { Inhibition of beta-catenin } \\
\text { degradation }\end{array}$ & LOF & $\begin{array}{l}\text { Familial adenomatous polyposis, } \\
\text { cancer }\end{array}$ \\
\hline WTX & $\begin{array}{l}\text { Inhibition of beta-catenin } \\
\text { degradation }\end{array}$ & LOF & Wilms tumor \\
\hline $\begin{array}{l}\text { Beta-catenin } \\
\text { (CTNNB1) }\end{array}$ & Enhancing of pro oncogene action & GOF & Cancer \\
\hline
\end{tabular}

LOF, loss of function; GOF, gain of function; LRP, low-density lipoprotein receptor; FEVR, familial exudative vitreoretinopathy. Modified from MacDonald et al., 2009 (47). 
components have been identified and found to be linked to altered bone mineral density (10-14). So in the last few years the interest for the WNT signalling pathways has been growing for their relevance in skeletal development, bone mass maintenance and potential therapeutic implications.

The WNT pathways involve all bone cells: osteoblasts, osteocytes and osteoclasts. Mesenchymal stem cells (MSC) resident in the bone cavity give rise to most marrow stromal cell lineages, including chondrocytes, osteoblasts, fibroblasts, adipocytes, endothelial cells, and myocytes (15). Osteoblasts are responsible for bone formation. Osteocytes are terminally differentiated osteoblasts embedded within the mineralized matrix that communicate changes in mechanical loading and extracellular environment to osteoblasts and osteoclasts on bone surface and so regulate bone remodeling and fracture repair (16). Osteoclasts originate from hematopoietic stem cells and are responsible for bone resorption (17). Several basic studies have suggested that WNT signalling enhances bone formation by regulating osteoblast and osteoclast proliferation and differentiation through well-characterized steps:

1) WNT signalling is crucial for the differentiation of osteoblasts from mesenchymal precursors (18), by shifting MSC differentiation from chondrocyte and adipocyte to osteoblast (19-23);

2) WNT signalling is associated with proliferation, maturation and survival of osteoblasts. A subgroup of WNT induces a cascade of intracellular events that stabilize beta-catenin, facilitating its transport to nucleus where it binds Lef1/Tcf transcription factors and alters gene expression to promote osteoblast expansion, proliferation, function, and survival (24);

3) WNT signalling is also implicated in the coupling of osteblast and osteoclast activity. The enhancing osteoblast differentiation ensues in increased synthesis and secretion of osteoprotegerin (OPG), a competitive inhibitor of receptor activator of nuclear factor kappa B (RANKL). It also interferes with
RANK-RANKL interaction which is essential for osteoclast maturation and activity. In this way WNT, indirectly, can block osteoclast differentiation. Thus, WNT signalling may be associated with both increased bone formation and inhibition of osteoclast-mediated bone resorption (25).

\section{THE WNT PATHWAYS}

WNTs trigger different signalling cascades. We can distinguish two different pathways: canonical and non-canonical which are depending on the typology of WNT, cell surface receptors present on recipient cells and on local concentration of WNT antagonists.

\section{The canonical WNT-beta catenin signal- ling}

The best-known pathway is the so-called canonical pathway that leads to stabilization and nuclear translocation of the betacatenin, normally present in the cytoplasm. A key component of canonical WNT pathway is Axin which negatively regulates WNT signalling by facilitating the phosphorylation and degradation of betacatenin. In absence of WNTs, beta-catenin is quickly sequestered and degraded by ubiquitin-mediated proteolysis (2, 24). Binding of certain WNTs (e.g. WNT3a) with specific cell surface receptors leads to inactivation of beta-catenin proteolysis also through the degradation of Axin (26). This way beta-catenin becomes stable, its cytoplasmic levels are increased and it can enter in the nucleus where it regulates the expression of target genes displacing corepressors from transcriptional factors (2). The WNT canonical pathway contributes to differentiation, proliferation and survival of osteoblasts (24) and it regulates the expression of OPG inhibiting osteoclastmediated bone resorption (25).

WNT pathways play a key role in determining the fate of MSC. In absence of $\beta$-catenin these cells do not differentiate into mature osteocalcin-expressing osteoblasts $(19,20)$ but only into chondrocytes. On the contrary, 
WNT canonical signalling prevents progenitor cells differentiating down the chondrocyte lineage and targeting them instead to the osteoblast lineage $(21,22)$. WNT signalling pathways promote osteoblastogenesis also by suppressing adipogene sis. Inducers of differentiation in one lineage often inhibit differentiation along the others. Thus, for example, peroxisome proliferator activated receptor gamma (PPAR-gamma) is a transcription factor that induces adipogenesis and inhibits osteoblastogenesis (27). Both canonical and non-canonical WNT pathways induce osteoblastogenesis and suppress adipogenesis by reducing the expression of PPAR-gamma $(23,28)$ (Fig. 1).

\section{The WNT-non-canonical pathways}

Sometimes WNTs do not activate the betacatenin canonical pathway but they rather trigger alternative intracellular events (non canonical pathways). Beta-catenin independent signalling are mediated by several kinases such as mitogen-activated protein, protein kinase and calcium/calmodulindependent protein kinase (23). These path-

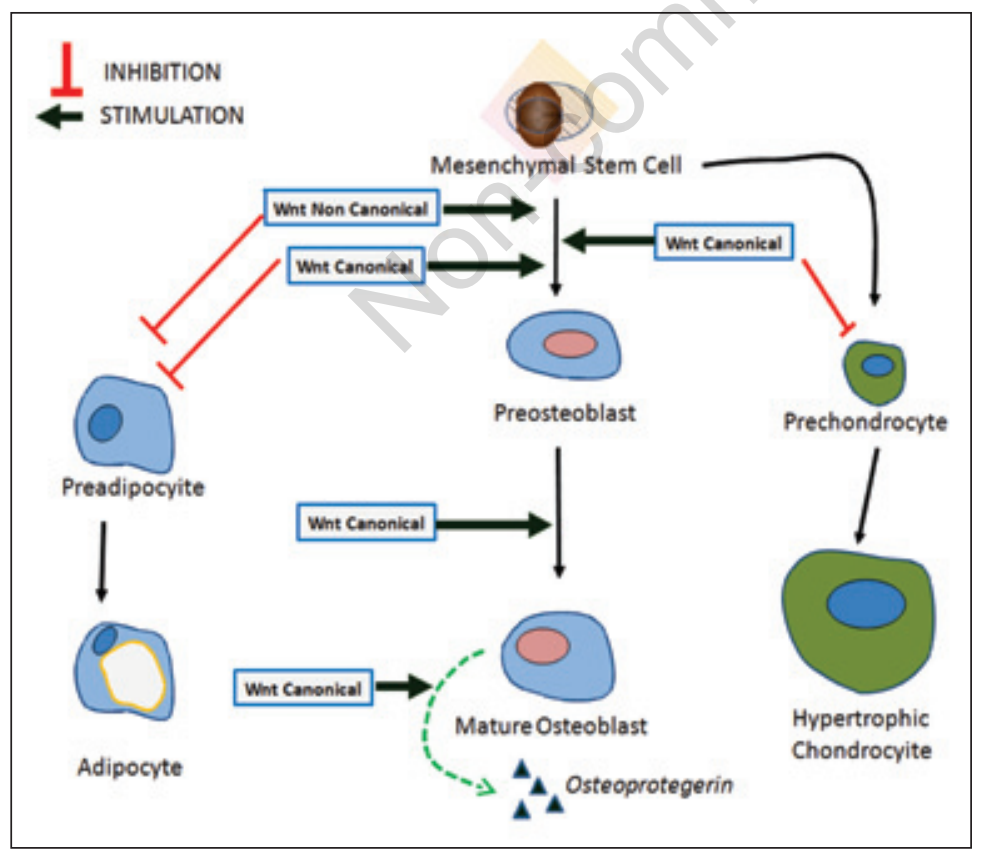

Figure 1 - The WNT pathway and cellular lines involved. It is showed how both the canonical and non-canonical pathways play a role in the maturation of osteoblasts and how the inhibition of WNT system can lead to a different fate for the mesenchymal stem cell. ways regulate cellular proliferation, differentiation, migration and polarity (2). The effects on bone are subjected to intensive investigation but it is likely that also noncanonical WNT signalling supports normal bone physiology in adults. In this context it should be emphasized that non canonical WNT ligands and their receptors are expressed in adult bone at level comparable to those for canonical WNT signalling pathways (23) but its role in supporting osteoblastogenesis is still poorly understood. A non-canonical WNT ligand (WNT5A) strongly suppresses transcription of PPARgamma and has emerged as an MSC fate determinant through shifting MSC differentiation from adipocyte to osteoblast (29). The timing of this non-canonical WNT action seems to be critical in inducing osteoblastogenesis over adipogenesis (23).

\section{Tipology of WNT}

WNTs are a family of secreted glycoproteins. The processing and secretion of all WNTs are under the control of seven-passtransmembrane protein called WNTless (30-32) that is expressed ubiquitously in human and rodent cells $(33,34)$. This indicates that WNTs are important for all cell type both during foetal and postnatal growth. Cells recognize WNTs through 10 Frizzled receptors and their co-receptors low-density lipoprotein receptor-related protein: LRP5 or LRP6 and potentially LRP4 (2). The large number of ligands and receptors and of their possible combinations contributes to widely variable cellular responses depending on the molecules present. Historically, two different metabolic pathways (canonical and non canonical) were identified based on their ability to activate beta catenin. In general, WNT1, WNT3a, WNT5a, WNT7a, WNT8a and WNT10a are considered activators of the canonical pathway, whereas WNT5a or WNT11 are best known for their ability to trigger non-canonical WNT signalling $(23,35)$. This distinction is not so clear since some WNTs may activate both pathways depending on the cellular contest and the presence of appropriate Frizzled receptors $(2,35)$. 


\section{WNT-RECEPTORS}

\section{Frizzleds}

WNTs exert their biological effects by binding and then activating cell surface receptors, called Frizzled, that are members of the $\mathrm{G}$ protein-coupled receptors superfamily. Like the other G protein-coupled receptors also Frizzleds can be considered membrane receptors with three basic regions (36):

1) the N-terminal, exofacial domains. These participate in binding WNT or other antagonists, with and without co-receptors like LDL receptor-related proteins: LRP5/6. The latter include members of the SFRP, of the Dkk family ligands and sclerostin (SCL) (36). Activation of the canonical pathway is initiated when WNT associates with FZ and LRP5/6, while the activation of non-canonical pathway seems to involve interaction of WNT with FZ but in absence of LRP5/6 (37);

2) a transmembrane central core composed of seven, hydrophobic alpha-helices that span the lipid bilayers;

3 ) at least three intracellular loops and a C-terminal tail that constitute the cytoplasmic domains- They are intimately involved in signal propagation first to heterotrimeric G-proteins and then to downstream signalling elements found in the cellular cytoplasm $(36,38)$.

\section{Low-density lipoprotein receptor-related proteins}

Low-density lipoprotein receptor-related proteins are plasma membrane receptors involved in lipid metabolism, transport and cellular signalling. The initiation of the WNT-beta catenin signalling cascade takes place when FZ form a complex together with WNT-ligands and with the WNT-coreceptors LRP5 or LRP6. These co-receptors exhibit a highly conserved domain structure and consist of a large extracellular domain, a small transmembrane region and a cytoplasmatic domain (39-41). LRP5 and 6 show low affinity for WNTs and high affinity for soluble antagonists such as SCL and Dkk1 (2) which are therefore essential for the regulation of WNT activation and inhibition.

LRP5 is required for efficient WNT signalling and beta-catenin activation in osteoblasts (2). It plays a key role in regulation of bone mass either through a direct control of osteoblast-lineage cells or indirectly in endocrine and paracrine manner, controlling bone formation by inhibiting serotonin synthesis in the duodenum (42).

LRP6 share 70\% amino acid identity with LRP5 and has many similar properties. This co-receptor contributes also to optimal parathyroid hormone (PTH) signalling in osteoblasts (43). Recently it has been shown that LRP6 plays an essential role in WNT3a/beta catenin signalling and inhibition of adipogenic differentiation of stem cells actions that cannot be replaced by LRP5 (44).

LRP4 is an emerging regulator of bone mass. It can antagonize canonical WNT pathway in vitro (45) and modulates several signalling pathways in skeletal and tooth development especially in craniofacial organogenesis (46).

The loss of function in LRP5 gene is involved in the osteoporosis pseudoganglioma syndrome, a recessive disorder characterized by low bone mass and abnormal eye vasculature $(5,47,48)$.

Conversely patients with autosomal dominant high bone mass diseases harbor LRP5 missense (gain-of-function) mutations (49), which are clustered in the LRP5 extracellular domain and render LRP5 resistant to binding and inhibition by the antagonist $\operatorname{SOST}(50,51)$ and DKK1 (52).

\section{WNT-antagonists}

Secreted WNT antagonists can inhibit WNT signalling by binding either WNTs or LRP5/6 co-receptors, leading in both cases to inhibition of the aggregation of the 3 components of the WNT pathway.

\section{Secreted frizzled-related proteins}

Secreted frizzled-related proteins (SFRPs) include 5 members of secreted, cysteinerich glycoproteins SFRPs that directly bind to WNTs/FZ complex, preventing their functional association with FZs on the cell 
surface (37). SFRP1 is the most extensively studied and its cysteine rich domain has homology with the FZ-WNT receptor (53, 54). Study on KO animals and cell cultures showed that the lack of SFRP1 is associated with high trabecular bone density similar to that seen during treatment with PTH $(55,56)$ while its overexpression in mice is associated with decreased bone density and with the prevention of the anabolic effect of PTH (57). SFRP1 might be involved also in glucocorticoid induced osteoporosis since its expression is increased by dexamethasone (58). It was also suggested that SFRP1 may also bind RANKL and then block osteoblast-induced osteoclastogenesis (59). This way SFRP1 might inhibits both osteoblast and osteoclast activity (58).

\section{Dickkopfs}

The Dickkopfs family comprises four members (Dkk1 to Dkk4) and a unique Dkk3 related protein named Soggy (37). DKK1 is the most studied member of the family, it is expressed and active in many tissue (60) and regulates bone mass in human. Dkk1 inhibits WNT-induced stabilisation of beta catenin by binding to LRP5/6. Dkk1 also interacts with another class of receptors (Kremen 1 and 2) to form a ternary complex (Kremen-Dkk1-LRP6) that blocks WNT-LRP6 signalling by inducing endocytosis and removal of WNT receptor from the plasma membrane (61). The internalisation of LRP5/6 with Kremen receptors seems to inhibit the degradation of Axin. Then it promotes the degradation of beta-catenin in order to inhibit the canonical WNT pathway (37). The antagonistic effect of Dkk1, mediated by LRP5/6, might be specific to the WNT beta-catenin pathway since the activation of non-canonical WNT pathway is not affected (62).

Dkk1 counteracts the WNT-beta-catenin effects on bone differentiation by promoting adipogenesis (60). WNT Beta-catenin pathway activation not only stimulates new bone formation but it also inhibits osteoclastogenesis by increasing OPG, the decoy protein for RANKL (25). In addition to bone formation impairment, Dkk1 overexpression shifts the OPG:RANKL ratio to favour bone resorption. At variance with SFRP which blunts both bone formation and bone resorption, Dkk1 inhibits bone formation and favours osteoclastic bone resorption.

The role played by other DKKs is less clear. The activity of Dkk3 and 4 appear similar to the Dkk1 one, but is apparently not expressed by bone cells (2). The molecular functions of Dkk2 are more complicated and vary with cellular context. Both Dkk1 and Dkk2 can bind to LRP6 (61) but Dkk2 can either antagonise either stimulate (37) WNT beta-catenin pathway. These opposing effects may be modulated by Kremer 2 which converts Dkk2 from agonist to antagonist of LRP6 (63). Moreover in the presence of high WNT7b levels DKK2 induce terminal osteoblast differentiation (64).

\section{Sclerostin}

Bone remodeling is the physiological process by which bone tissue is continually removed and replaced on the surface of trabecular bone and within the Haversian systems of cortical bone.

This process requires the activity of three different types of cells - osteoclasts (bone resorbing cells), osteoblasts (bone forming cells), and osteocytes. Osteocytes are former osteoblasts that were trapped in the newly formed bone matrix. They communicate with one another and with bone lining cells of bone surface through a network of cytoplasmic connections (65) and are cells that detect loads applied to bone. Over loading is associated with local stimulation of bone formation and vice-versa. This mechanoregulatory mechanism is mediated by SCL expressed almost uniquely by osteocytes.

Sclerostin is a monomeric glycoprotein that antagonizes WNT/beta-catenin signalling (66) in osteoblasts as DKK1, by binding to LRP5 and LRP6 and preventing their association with FZ and WNTs. This results in the inhibition of osteoblast differentiation, activity, and survival (67).

SCL is the product of the SOST gene, which is mutated and down-regulated in patients with sclerosteosis and van Buchem's dis- 
ease $(68,69)$ two rare bone sclerosing disorders characterized by endosteal hyperostosis, progressive generalized osteosclerosis, and high bone mass associated with increased osteoblastic activity and elevated bone formation markers (70).

As it often happens, identification of the genetic and molecular origin of a rare disease has revealed an important mechanism in normal physiological processes with potential implication for the development of new treatments for common diseases. The concept that osteocytes have a mechanosensing role with sclerostin as a key signalling protein for osteoblasts is supported by several preclinical studies (71). Bone loading in animals is associated with decreased expression of SCL by osteocytes and with an increase in bone formation while bone unloading is associated with an increase in SOST transcription (72), up-regulation of sclerostin, and a decrease in WNT/betacatenin signalling (73).

Bone density and mechanical strength are elevated in Sost knockout mice $(74,75)$ whereas transgenic overexpression of Sost induces osteopenia $(76,77)$.

All these data suggest that disuse osteoporosis may in part be mediated by sclerostin-related inhibition of osteoblastic bone formation and that SCL is an important negative regulator of bone formation. Evidence points out that in addition to its anti-anabolic role, sclerostin has a catabolic activity. Sclerostin dose-dependently up-regulates the expression of RANKL mRNA and down-regulates the expression of OPG mRNA, causing an increase in the RANK:OPG mRNA ratio (78), enhancing osteoclast activity. This action seems similar to DKK1 and is due to the inhibition of WNT canonical pathway in which betacatenin induces an increase in synthesis and secretion of OPG (25).

SCL seems also to be an important mediator of the anabolic effect of PTH in bone. PTH suppresses SCL expression both in vitro and in vivo $(79,80)$ while over-expression of SOST prevent in rats the anabolic response to PTH administration $(81,82)$. Unlike DKKs and SFRP, SCL is produced primarily by bone cells and is abundant es- pecially in the osteocytic canalicular system $(83,84)$ SCL has also been detected in cementocytes in teeth, mineralized hypertrophic chondrocytes in the growth plate, and osteoarthritic cartilage $(85,86)$. SCL may also be expressed by osteoclast precursors but not in by mature osteoclasts (87).

The WNT pathway with their several components seem to have a key role in bone development, remodeling, and repair although there is still much to understand and to study and much remains to be discovered. However already now our knowledge allows us to recognize this pathway as a possible source of new therapeutic strategies for common disease characterized by altered bone mass as osteoporosis, of high socioeconomic burden (88). Some of these treatments are already in advanced stage of development (89).

Moreover this pathway is probably involved in the metabolic response to treatment with bone active agents used for the treatment of post-menopausal and male osteoporosis (90). In fact some of their effects on bone turnover are related with changes in the WNT/beta-catenin signalling. For example treatment with estrogens or raloxifene, but

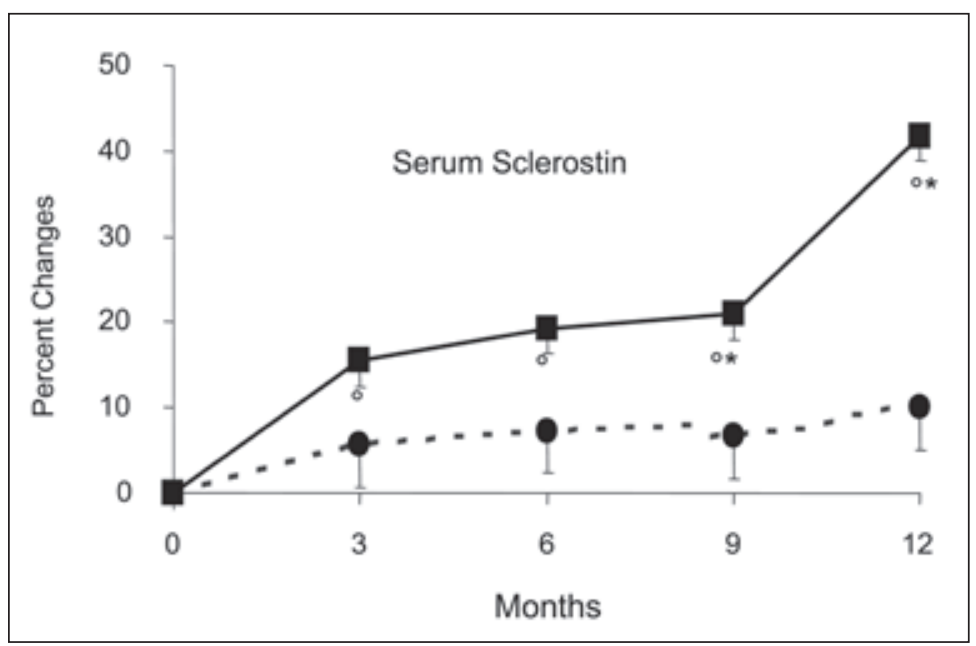

Figure 2 - The increase in serum sclerostin during treatment with neridronate versus placebo. The association between neridronate treatment and increased sclerostin levels suggests that the inhibition of bone formation observed after extended treatment with bisphosphonates might be mediated, at least in part, by an increase in sclerostin (modified from Gatti et al., 2011 (94)). 
not with androgens, is associated with a decrease in SCL levels $(91,92)$.

For this reason we decided to study both the changes in the WNT-antagonists serum levels (SCL and DKK1) during antiresorptive (bisphosphonates and denosumab) and anabolic treatment (teriparatide) (93).

Bisphosphonates are known to directly suppress osteoclastic activity, but the suppression of bone resorption is typically associated with a later decrease of bone formation.

To determine whether this decrease in bone formation is associated with changes in serum levels of SCL or DKK1, 107 patients were treated with either monthly intramuscular neridronate or placebo (88). Serum C-terminal telopeptide of type I collagen (sCTX, a bone-resorption marker) and bone alkaline phosphatase (bAP, a bone-formation marker) decreased, as expected, during neridronate treatment. Serum DKK1 remained unchanged at all time points while serum SCL increased versus placebo group gradually and significantly only in patients treated with two upper doses ( 25 or $50 \mathrm{mg}$ neridronate monthly), reaching 138-148\% of baseline values $(\mathrm{P}<0.001)$ (Fig. 2). In consideration of the anti-anabolic effects of sclerostin on bone formation, the association between neridronate treatment and increased sclerostin levels suggests that the inhibition of bone formation observed after extended treatment with bisphosphonates might be mediated, at least in part, by an increase in sclerostin. Indeed we found a negative correlation $(\mathrm{P}<0.001)$ between the changes in bAP and sclerostin but causal link remains hypothetical (94).

This effect of bisphosphonates on WNTantagonist appears to be different from that we found in patients treated with denosumab (95), an antiresorptive drug that, suppressing RANKL activity, lowers the number not only of actively resorbing osteoclasts (as bisphosphonates do) but also of osteoclast precursors. In our study denosumab therapy was found to be associated with increasing SCL levels (as bisphosphonates treatment) but it was also associated with declining serum levels of DKK1 (95) and this might explain the apparent per- sistent slight positive unbalance between suppressed bone resorption and formation during denosumab treatment (96).

The WNT-pathway is also involved in the response to bone anabolic agents. It has been reported that treatment with analogs of PTH or teriparatide is associated with decreases in serum SCL (97-99). These observations strongly suggest that the positive effect of PTH on osteoblast activity is at least in part mediated by changes in the $\mathrm{WNT} / \beta$ catenin signalling. It was also found that the effect of teriparatide on SOST disappears within a few months and that long-term treatment is associated with an increase in DKK1 (100). This might explains the loss of the bone anabolic effect of teriparatide after 18-24 months of continuous treatment.

In conclusion the WNT-pathway and in particular its antagonists SCL and DKK1 seems to play a key role in the regulation of bone remodeling in a number of clinical conditions and during treatment with bone active agents, such as bisphosphonates, but not only. Their effects become relevant especially in the course of long-term treatments.

\section{REFERENCES}

1. Nusse R, Varmus HE. Many tumors induced by the mouse mammary tumor virus contain a provirus integrated in the same region of the host genome. Cell. 1982; 31: 99-109.

2. Monroe DG, McGee-Lawrence ME, Oursler MJ, Westendorf JJ. Update on Wnt signalling in bone cell biology and bone disease. Gene. 2012; 492: 1-18.

3. Verkaar F, Zaman GJ. New avenues to target Wnt $/ \beta$-catenin signalling. Drug Discov Today. 2011; 16: 35-41.

4. Verkaar F, Zaman GJ. A model for signalling specificity of Wnt/Frizzled combinations through co-receptor recruitment. FEBS Lett. 2010; 584: 3850-4.

5. Gong Y, Slee RB, Fukai N, Rawadi G, Roman-Roman S, Reginato AM, et al. LDL receptor-related protein 5 (LRP5) affects bone accrual and eye development. Cell. 2001; 107: 513-23.

6. Ai M, Holmen SL, Van Hul W, Williams BO, Warman ML. Reduced affinity to and inhibition by DKK1 form a common mechanism by which high bone mass-associated mis- 
sense mutations in LRP5 affect canonical Wnt signalling. Mol Cell Biol. 2005; 25: 4946-55.

7. Boyden LM, Mao J, Belsky J, Mitzner L, Farhi A, Mitnick MA, et al. High bone density due to a mutation in LDL-receptor-related protein 5. N Engl J Med. 2002; 346: 151321.

8. Van Wesenbeeck L, Cleiren E, Gram J, Beals RK, Bénichou O, Scopelliti D, et al. Six novel missense mutations in the LDL receptorrelated protein 5 (LRP5) gene in different conditions with an increased bone density. Am J Hum Genet. 2003; 72: 763-71.

9. Baron R, Hesse E. Update on bone anabolics in osteoporosis treatment: rationale, current status, and perspectives. J Clin Endocrinol Metab. 2012; 97: 311-25.

10. Kiel DP, Ferrari SL, Cupples LA, Karasik D, Manen D, Imamovic A, et al. Genetic variation at the low-density lipoprotein receptorrelated protein 5 (LRP5) locus modulates Wnt signaling and the relationship of physical activity with bone mineral density in men. Bone. 2007; 40: 587-96.

11. Riancho JA, Olmos JM, Pineda B, GarcíaIbarbia C, Pérez-Núñez MI, Nan DN, et al. Wnt receptors, bone mass, and fractures: gene-wide association analysis of LRP5 and LRP6 polymorphisms with replication. Eur J Endocrinol. 2011; 164: 123-31.

12. Rivadeneira F, Styrkársdottir U, Estrada K, Halldórsson BV, Hsu Y-H, Richards JB, et al. Twenty bone-mineral-density loci identified by large-scale meta-analysis of genomewide association studies. Nat Genet. 2009; 41: 1199-206.

13. Sims A-M, Shephard N, Carter K, Doan T, Dowling A, Duncan EL, et al. Genetic analyses in a sample of individuals with high or low BMD shows association with multiple Wnt pathway genes. J Bone Miner Res. 2008; 23: 499-506.

14. Van Meurs JBJ, Trikalinos TA, Ralston SH, Balcells S, Brandi ML, Brixen K, et al. Large-scale analysis of association between LRP5 and LRP6 variants and osteoporosis. JAMA. 2008; 299: 1277-90.

15. Del Fattore A, Capannolo M, Rucci N. Bone and bone marrow: the same organ. Arch Biochem Biophys. 2010; 503: 28-34.

16. Bonewald LF. The amazing osteocyte. J Bone Miner Res. 2011; 26: 229-38.

17. Colonna M. TREMs in the immune system and beyond. Nat Rev Immunol. 2003; 3: 445-53.

18. Leucht P, Minear S, Ten Berge D, Nusse R, Helms JA. Translating insights from development into regenerative medicine: the function of Wnts in bone biology. Semin Cell Dev Biol. 2008; 19: 434-43.

19. Hu H, Hilton MJ, Tu X, Yu K, Ornitz DM,
Long F. Sequential roles of Hedgehog and Wnt signaling in osteoblast development. Development. 2005; 132: 49-60.

20. Rodda SJ, McMahon AP. Distinct roles for Hedgehog and canonical Wnt signalling in specification, differentiation and maintenance of osteoblast progenitors. Development. 2006; 133: 3231-4.

21. Day TF, Guo X, Garrett-Beal L, Yang Y. Wnt/beta-catenin signaling in mesenchymal progenitors controls osteoblast and chondrocyte differentiation during vertebrate skeletogenesis. Dev Cell. 2005; 8: 739-50.

22. Hill TP, Später D, Taketo MM, Birchmeier W, Hartmann C. Canonical Wnt/beta-catenin signaling prevents osteoblasts from differentiating into chondrocytes. Dev Cell. 2005; 8: 727-38.

23. Takada I, Kouzmenko AP, Kato S. Wnt and PPARgamma signalling in osteoblastogenesis and adipogenesis. Nat Rev Rheumatol. 2009; 5: 442-7.

24. Westendorf JJ, Kahler RA, Schroeder TM. Wnt signalling in osteoblasts and bone diseases. Gene. 2004; 341: 19-39.

25. Glass DA 2nd, Bialek P, Ahn JD, Starbuck M, Patel MS, Clevers H, et al. Canonical Wnt signaling in differentiated osteoblasts controls osteoclast differentiation. Dev Cell. 2005; 8: 751-64.

26. Mao J, Wang J, Liu B, Pan W, Farr GH 3rd, Flynn C, et al. Low-density lipoprotein receptor-related protein-5 binds to Axin and regulates the canonical Wnt signalling pathway. Mol. Cell 2001; 7: 801-9.

27. Schwartz AV, Sellmeyer DE, Vittinghoff E, Palermo L, Lecka-Czernik B, Feingold KR, et al. Thiazolidinedione use and bone loss in older diabetic adults. J Clin Endocrinol Metab. 2006; 91: 3349-54.

28. Bennett CN, Longo KA, Wright WS, Suva LJ, Lane TF, Hankenson KD, et al. Regulation of osteoblastogenesis and bone mass by Wnt10b. Proc Natl Acad Sci USA. 2005; 102: 3324-9.

29. Takada I, Mihara M, Suzawa M, Ohtake F, Kobayashi S, Igarashi $\mathrm{M}$, et al. A histone lysine methyltransferase activated by noncanonical Wnt signalling suppresses PPARgamma transactivation. Nat Cell Biol. 2007; 9: 1273-85.

30. Banziger C, Soldini D, Schutt C, Zipperlen P, Hausmann G, Basler K. Wntless, a conserved membrane protein dedicated to the secretion of Wnt proteins from signalling cells. Cell. 2006; 125: 509-22.

31. Bartscherer $K$, Pelte $N$, Ingelfinger $D$, Boutros M. Secretion of Wnt ligands requires Evi, a conserved transmembrane protein. Cell. 2006; 125: 523-33.

32. Goodman RM, Thombre S, Firtina Z, Gray D, Betts D, Roebuck J, et al. Sprinter: a nov- 
el transmembrane protein required for $\mathrm{Wg}$ secretion and signaling. Development. 2006; 133: 4901-11.

33. Jin J, Morse M, Frey C, Petko J, Levenson R. Expression of GPR177 (Wntless/Evi/ Sprinter), a highly conserved Wnt-transport protein, in rat tissues, zebrafish embryos, and cultured human cells. Dev Dyn. 2010; 239: 2426-34.

34. Yu HM, Jin Y, Fu J, Hsu W. Expression of Gpr177, a Wnt trafficking regulator, in mouse embryogenesis. Dev Dyn. 2010; 239: 2102-9.

35. Rao TP, Kühl M. An updated overview on Wnt signalling pathways: a prelude for more. Circ Res. 2010; 106: 1798-806.

36. Wang HT, Liu T, Malbon CC. Structurefunction analysis of Frizzleds. Cell Signal. 2006; 18: 934-41

37. Kawano Y, Kypta R. Secreted antagonists of the Wnt signalling pathway. J Cell Sci. 2003; 116: 2627-34.

38. Koval A, Purvanov V, Egger-Adam D, Katanaev VL. Yellow submarine of the Wnt/ Frizzled signalling: submerging from the $G$ protein harbor to the targets. Biochem Pharmacol. 2011; 82: 1311-9.

39. Brown SD, Twells RC, Hey PJ, Cox RD, Levy ER, Soderman AR, et al Isolation and characterization of LRP6, a novel member of the low density lipoprotein receptor gene family. Biochem. Biophys. Res. Commun. 1998; 248: 879-88.

40. Kim DH, Inagaki Y, Suzuki T, Ioka RX, Yoshioka SZ, Magoori K, et al. A new low density lipoprotein receptor related protein, LRP5, is expressed in hepatocytes and adrenal cortex, and recognizes apolipoprotein E. J Biochem. 1998; 124: 1072-6.

41. He X, Semenov M, Tamai K, Zeng X. LDL receptor-related proteins 5 and 6 in Wnt/beta-catenin signalling: arrows point the way. Development. 2004; 131: 1663-77.

42. Yadav VK, Ryu JH, Suda N, Tanaka KF, Gingrich JA, Schütz G, et al. Lrp5 controls bone formation by inhibiting serotonin synthesis in the duodenum. Cell. 2008; 135: 825-37.

43. Wan M, Yang C, Li J, Wu X, Yuan H, Ma H, et al. Parathyroid hormone signaling through low-density lipoprotein-related protein 6 . Genes Dev. 2008; 22: 2968-79.

44. Peröbner I, Karow M, Jochum M, Neth P. LRP6 mediates Wnt/ $\beta$-catenin signalling and regulates adipogenic differentiation in human mesenchymal stem cells. Int J Biochem Cell Biol. 2012; 44: 1970-82.

45. Johnson EB, Hammer RE, Herz J. Abnormal development of the apical ectodermal ridge and polysyndactyly in Megf7-deficient mice. Hum Mol Genet. 2005; 14: 3523-38.

46. Ohazama A, Porntaveetus T, Ota MS, Herz
J, Sharpe PT. Lrp4: A novel modulator of extracellular signalling in craniofacial organogenesis. Am J Med Genet A 2010; 152: 2974-83.

47. MacDonald BT, Tamai K, He X. Wnt/betacatenin signaling: components, mechanisms, and diseases. Dev Cell. 2009; 17: 9-2.

48. Laine CM, Chung BD, Susic M, Prescott T, Semler O, Fiskerstrand T, et al. Novel mutations affecting LRP5 splicing in patients with osteoporosis-pseudoglioma syndrome (OPPG). Eur J Hum Genet. 2011; 19: 87581.

49. Levasseur R, Lacombe D, de Vernejoul MC. LRP5 mutations in osteoporosis-pseudoglioma syndrome and high-bone-mass disorders. Joint Bone Spine. 2005; 72: 207-14.

50. Ellies DL, Viviano B, McCarthy J, Rey JP, Itasaki N, Saunders S, et al. Bone density ligand, Sclerostin, directly interacts with LRP5 but not LRP5G171V to modulate Wnt activity. J Bone Miner Res. 2006; 21: 173849.

51. Semenov MV, He X. LRP5 mutations linked to high bone mass diseases cause reduced LRP5 binding and inhibition by SOST. J Biol Chem. 2006; 281: 38276-84.

52. Ai M, Holmen SL, Van Hul W, Williams BO, Warman ML. Reduced affinity to and inhibition by DKK form a common mechanism by which high bone mass-associated missense mutations in LRP5 affect canonical Wnt signaling. Mol Cell Biol. 2005; 25: 4946-55.

53. Schulte G. International Union of Basic and Clinical Pharmacology. LXXX. The class Frizzled receptors. Pharmacol Rev. 2010; 62: 632-67.

54. Banyai L, Patthy L. The NTR module: domains of netrins, secreted frizzled related proteins, and type I procollagen C-proteinase enhancer protein are homologous with tissue inhibitors of metalloproteases. Protein Sci. 1999; 8: 1636-42.

55. Bodine PVN, Zhao W, Kharode YP, Bex FJ, Lambert A-J, Goad MB, et al. The Wnt antagonist secreted frizzled-related protein-1 is a negative regulator of trabecular bone formation in adult mice. Mol Endocrinol. 2004; 18: 1222-37.

56. Bodine PV, Seestaller-Wehr L, Kharode YP, Bex FJ, Komm BS. Bone anabolic effects of parathyroid hormone are blunted by deletion of the Wnt antagonist secreted frizzledrelated protein-1. J Cell Physiol. 2007; 210: 352-7.

57. Yao W, Cheng Z, Shahnazari M, Dai W, Johnson ML, Lane NE. Overexpression of secreted frizzled-related protein 1 inhibits bone formation and attenuates parathyroid hormone bone anabolic effects. J Bone Miner Res. 2010; 25: 190-9.

58. Wang F-S, Lin C-L, Chen Y-J, Wang C-J, 
Yang KD, Huang Y-T, et al. Secreted frizzled-related protein 1 modulates glucocorticoid attenuation of osteogenic activities and bone mass. Endocrinology. 2005; 146: 241523.

59. Hausler KD, Horwood NJ, Chuman Y, Fisher JL, Ellis J, Martin TJ, et al. Secreted frizzled-related protein-1 inhibits RANKL-dependent osteoclast formation. J Bone Miner Res. 2004; 19: 1873-81.

60. Pinzone JJ, Hall BM, Thudi NK, Vonau M, Qiang Y-W, Rosol TJ, et al. The role of Dickkopf-1 in bone development, homeostasis, and disease. Blood. 2009; 113: 517-25.

61. Mao B, Wu W, Davidson G, Marhold J, Li M, Mechler BM, et al. Kremen proteins are Dickkopf receptors that regulate $\mathrm{Wnt} /$ betacatenin signalling. Nature. 2002; 417: 664-7.

62. Semenov MV, Tamai K, Brott BK, Kuhl M, Sokol S, et al. Head inducer Dickkopf-1 is a ligand for Wnt coreceptor LRP6. Curr Biol. 2001; 11: 951-61.

63. Mao B, Niehrs C. Kremen 2 modulates Dickkopf 2 activity during Wnt/LRP6 signalling. Gene 2003; 302: 179-83.

64. Li X, Liu P, Liu W, Maye P, Zhang J, Zhang $\mathrm{Y}$, et al. Dkk2 has a role in terminal osteoblast differentiation and mineralized matrix formation. Nat Genet. 2005; 37: 945-52.

65. Bonewald LF. Osteocytes. In: Rosen V, ed. Primer on the metabolic bone diseases and disorders of mineral metabolism, 7th ed. Washington DC: American Society for Bone and Mineral Research; 2008; 22-7.

66. Li X, Zhang Y, Kang H, Liu W, Liu P, Zhang J, et al. Sclerostin binds to LRP5/6 and antagonizes canonical Wnt signalling. J Biol Chem. 2005; 280: 19883-7.

67. Baron R, Rawadi G. Targeting the Wnt/betacatenin pathway to regulate bone formation in the adult skeleton. Endocrinology. 2007; 148: 2635-43.

68. Balemans W, Ebeling M, Patel N, Van Hul $\mathrm{E}$, Olson P, Dioszegi M, et al. Increased bone density in sclerosteosis is due to the deficiency of a novel secreted protein (SOST). Hum Mol Genet. 2001; 10: 537-43.

69. Brunkow ME, Gardner JC, Van Ness J, Paeper BW, Kovacevich BR, Proll S, et al. Bone dysplasia sclerosteosis results from loss of the SOST gene product, a novel cystine knot-containing protein. Am J Hum Genet. 2001; 68: 577-89.

70. Wergedal JE, Veskovic K, Hellan M, Nyght C, Balemans W, Libanati C, et al. Patients with Van Buchem disease, an osteosclerotic genetic disease, have elevated bone formation markers, higher bone density, and greater derived polar moment of inertia than normal. J Clin Endocrinol Metab. 2003; 88: 5778-83.

71. Lewiecki EM. Sclerostin: a novel target for intervention in the treatment of osteoporosis. Discov Med. 2011; 12: 263-73.

72. Robling AG, Niziolek PJ, Baldridge LA, Condon KW, Allen MR, Alam I, et al. Mechanical stimulation of bone in vivo reduces osteocyte expression of Sost/sclerostin. J Biol Chem. 2008; 283: 5866-75.

73. Lin C, Jiang X, Dai Z, Guo X, Weng T, Wang $\mathrm{J}$, et al. Sclerostin mediates bone response to mechanical unloading through antagonizing Wnt/beta-catenin signalling. J Bone Miner Res. 2009; 24: 1651-61.

74. Krause C, Korchynskyi O, de Rooij K, Weidauer SE, de Gorter DJJ, van Bezooijen RL, et al. Distinct modes of inhibition by sclerostin on bone morphogenetic protein and Wnt signaling pathways. J Biol Chem. 2010; 285 : 41614-26.

75. Li X, Ominsky MS, Niu Q-T, Sun N, Daugherty B, D'Agostin D, et al. Targeted deletion of the sclerostin gene in mice results in increased bone formation and bone strength. $\mathrm{J}$ Bone Miner Res. 2008; 23: 860-9.

76. Loots GG, Kneissel M, Keller H, Baptist M, Chang J, Collette NM, et al. Genomic deletion of a long-range bone enhancer misregulates sclerostin in Van Buchem disease. Genome Res. 2005; 15: 928-35.

77. Winkler DG, Sutherland MK, Geoghegan JC, Yu C, Hayes T, Skonier JE, et al. Osteocyte control of bone formation via sclerostin, a novel BMP antagonist. EMBO J. 2003; 22: 6267-76.

78. Wijenayaka AR, Kogawa M, Lim HP, Bonewald LF, Findlay DM, Atkins GJ. Sclerostin stimulates osteocyte support of osteoclast activity by a RANKL-dependent pathway. PLoS One. 2011; 6: e25900.

79. Bellido T, Ali AA, Gubrij I, Plotkin LI, Fu Q, O'Brien CA, et al. Chronic elevation of parathyroid hormone in mice reduces expression of sclerostin by osteocytes: a novel mechanism for hormonal control of osteoblastogenesis. Endocrinology. 2005; 146: 4577-83.

80. Keller H, Kneissel M. SOST is a target gene for PTH in bone. Bone. 2005; 37: 148-58.

81. Kramer I, Loots GG, Studer A, Keller H, Kneissel M. Parathyroid hormone (PTH)induced bone gain is blunted in SOST overexpressing and deficient mice. J Bone Miner Res. 2010; 25: 178-89.

82. O'Brien CA, Plotkin LI, Galli C, Goellner JJ, Gortazar AR, Allen MR, et al. Control of bone mass and remodeling by PTH receptor signaling in osteocytes. PLoS ONE. 2008; 3 : e2942.

83. Van Bezooijen RL, Roelen BAJ, Visser A, van der Wee-Pals L, de Wilt E, Karperien M, et al. Sclerostin is an osteocyte-expressed negative regulator of bone formation, but not a classical BMP antagonist. J Exp Med. 2004; 199: 805-14. 
84. Winkler DG, Sutherland MK, Geoghegan JC, Yu C, Hayes T, Skonier JE, et al. Osteocyte control of bone formation via sclerostin, a novel BMP antagonist. EMBO J. 2003; 22: 6267-76.

85. Chan BY, Fuller ES, Russell AK, Smith SM, Smith MM, Jackson MT, et al. Increased chondrocyte sclerostin may protect against cartilage degradation in osteoarthritis. Osteoarthr Cartil. 2011; 19: 874-85.

86. Van Bezooijen RL, Bronckers AL, Gortzak RA, Hogendoorn PCW, van der Wee-Pals L, Balemans W, et al. Sclerostin in mineralized matrices and van Buchem disease. J Dent Res. 2009; 88: 569-74.

87. Pederson L, Ruan M, Westendorf JJ, Khosla S, Oursler MJ. Regulation of bone formation by osteoclasts involves Wnt/BMP signalling and the chemokine sphingosine-1-phosphate. PNAS. 2008; 105: 20764-9.

88. Rossini M, Piscitelli P, Fitto F, Camboa P, Angeli A, Guida G, et al. Incidence and socioeconomic burden of hip fractures in Italy. Reumatismo. 2005; 57: 97-102.

89. Padhi D, Jang G, Stouch B, Fang L, Posvar E. Single-dose, placebo-controlled, randomized study of AMG 785, a sclerostin monoclonal antibody. J Bone Miner Res. 2011;26: 19-26.

90. Adami S, Bertoldo F, Brandi ML, Cepollaro C, Filipponi P, Fiore E, et al. [Guidelines for the diagnosis, prevention and treatment of osteoporosis]. Reumatismo. 2009; 61: 26084.

91. Mödder UI, Clowes JA, Hoey K, Peterson JM, McCready L, Oursler MJ, et al. Regulation of circulating sclerostin levels by sex steroids in women and in men. J Bone Mineral Res. 2011; 26: 27-34.

92. Chung YE, Lee SH, Lee SY, Kim SY, Kim $\mathrm{HH}$, Mirza FS, et al. Long-term treatment with raloxifene, but not bisphosphonates, reduces circulating sclerostin levels in post- menopausal women. Osteoporos Int. 2012; 23: 1235-43.

93. Viapiana O, Fracassi E, Troplini S, Idolazzi L, Rossini M, Adami S, et al. Sclerostin and DKK1 in primary hyperparathyroidism. Calcif Tissue Int. 2013; 92: 324-9.

94. Gatti D, Viapiana O, Adami S, Idolazzi L, Fracassi E, Rossini M. Bisphosphonate treatment of postmenopausal osteoporosis is associated with a dose dependent increase in serum sclerostin. Bone. 2012; 50: 739-42.

95. Gatti D, Viapiana O, Fracassi E, Idolazzi L, Dartizio C, Povino MR, et al. Sclerostin and DKK1 in postmenopausal osteoporosis treated with denosumab. J Bone Miner Res 2012; 27: 2259-63.

96. Rossini M, Gatti D, Adami S. Involvement of WNT/ $\beta$-catenin signaling in the treatment of osteoporosis. Calcif Tissue Int. 2013; 93: 121-32.

97. Drake MT, Srinivasan B, Mödder UI, Peterson JM, McCready LK, Riggs BL, et al. Effects of parathyroid hormone treatment on circulating sclerostin levels in postmenopausal women. J Clin Endocrinol Metab. 2010; 95: 5056-62.

98. Yu EW, Kumbhani R, Siwila-Sackman E, Leder BZ. Acute decline in serum sclerostin in response to PTH infusion in heakthy men. J Clin Endocrinol Metab. 2011; 96: E184851.

99. Piemonte S, Romagnoli E, Bratengeier C, Woloszczuk W, Tancredi A, Pepe J, et al. Serum sclerostin levels decline in postmenopausal women with osteoporosis following treatment with intermittent PTH. J Endocrinol Invest. 2012; 35: 866-8.

100. Gatti D, Idolazzi L, Fracassi E, Rossini M, Adami S. The waning of teriparatide effect on bone formation markers in postmenopausal osteoporosis is associated with increasing serum levels of DKK1. J Clin Endocrinol Metab. 2011; 96: 1555-9.0 